\title{
DISCUSSION
}

\section{A non-linear elastic/perfectly plastic analysis for plane strain undrained expansion tests}

\author{
M. D. BOLTON and R. W. WhitTLE (1999). Géotechnique 49, No. 1, 133-141
}

\section{B. Ladanyi and V. Silvestri, École Polytechnique, Montréal, Canada}

In their interesting Technical Note, in which they offer one possible alternative method for the interpretation of self boring pressuremeter test (SBPT) in clays, the authors have made certain statements which merit some additional comments. They state that in SBPT interpretation, 'it is common practice to reduce such data to fundamental strength and stiffness properties using analyses that assume the ground response to loading is simple elastic/perfectly plastic'. This is a very strange statement, because it is well known that, since 1972, most investigators have been using one of the methods based on the discretization of the stress-strain curve for pressuremeter test interpretation in clays (e.g. Ladanyi, 1972; Palmer, 1972). The discussers have been using with success the Ladanyi method since that time. They did not find it to be 'awkward', as stated by the authors; it made it possible to follow closely the whole stress-strain curve of the soil, and to detect the tensile cracking point of the test (e.g. Ladanyi \& Johnston, 1973), all without making any a priori assumptions concerning the stress-strain behaviour of the soil.

For SBPT interpretation purposes, the authors propose, as an alternative, the use of a stress-strain model for clay, composed of a power law and a straight line, as shown in their Fig. 2, and then they develop the complete solution of cylindrical cavity expansion based on that law. In this connection, it is interesting to note that complete solutions for expansion of both spherical and cylindrical cavities, based on exactly the same assumption, were published about 25 years ago for $\phi=0$ and $\phi>0$ materials by Ladanyi \& Johnston (1974) and Ladanyi (1975). For example, equation (14) in the Technical Note is found to be identical to equation (35) in Ladanyi (1975).

However, in the two aforementioned papers, the non-linear elastic/perfectly plastic solution was used only in connection with creep and creep rupture of frozen soils. It was not used in connection with pressuremeter test interpretation in unfrozen clays, first because it was considered that there is no sense in imposing any particular stress-strain law on the soil, and second because it is difficult to accept that the soil stiffness tends to infinity when shear strain tends to zero, as implied by the power law. In that respect, a better assumption may be that proposed by Denby \& Clough (1980), who use a hyperbolic stress-strain law as a basis for their pressuremeter test interpretation.

L. F. Cao, Hyundai Engineering and Construction Co. Ltd, Singapore

The authors present a useful solution to the undrained expan- sion of a cylindrical cavity in a non-linear elastic/perfectly plastic material. The most interesting find may be the determination of non-linear stiffness from the unload-reload loops of a pressuremeter test. The difference between the non-linear analysis and linear analysis in the estimation of the in situ horizontal stress may not be significant.

It is well known that the unloading curve of a pressuremeter test is significantly affected by creep and consolidation in a clayey layer. The authors suggested using the reloading curve of determine $\alpha$ and $\beta$. In the interpretation of reload curves, the authors make an important assumption that the power law function can be written as following in the non-linear elastic stage:

$$
\tau=\tau_{\mathrm{r}}=\alpha\left(\gamma-\gamma_{\mathrm{r}}\right)^{\beta}
$$

where $\gamma_{\mathrm{r}}$ and $\tau_{\mathrm{r}}$ are the shear strain and shear stress prior to reloading, respectively. However, the values of $\gamma_{\mathrm{r}}$ and $\tau_{\mathrm{r}}$ may affect the determination of $\alpha$ and $\beta$. Further study on the laboratory tests is needed.

For a cylindrical cavity expansion in an isotropically consolidated soil, the yield strain $\gamma_{\mathrm{y}}$ of soil during cavity expansion can be calculated from equation (27) with $\gamma_{\mathrm{r}}=0$ and $\tau_{\mathrm{r}}=0$ when the values of $c_{\mathrm{u}}, \alpha$ and $\beta$ are obtained. The authors suggested using equation (19), which is wrongly printed. Determination of $\gamma_{\mathrm{y}}$ by equation (19) requires the cavity reference pressure $p_{0}$ of in situ horizontal stress $\sigma_{\mathrm{ho}}$. The values of $r_{\mathrm{y}}$ and $G_{\mathrm{y}}$ for the SBP tests in London clay and Singapore marine clay calculated by using equations (17) and (27) are presented in Table 2. Based on the linear elastic analysis, the shear modulus $G_{\text {ur }}$ can be obtained from the unload-reload loops. The values of $G_{\mathrm{ur}}$ are larger than those of $G_{\mathrm{y}}$, as shown in Table 2. Correspondingly, the values of $\gamma_{\mathrm{y}}$, obtained from the linear analysis are smaller than those from the non-linear analysis

Having obtained $\gamma_{\mathrm{y}}, p_{\text {Limit }}, c_{\mathrm{u}}$ and $\beta, p_{0}$ can be calculated by using equation (14). The values of $p_{0}$ are shown in Table 2. It is interesting to note that the values of $p_{0}$ obtained from the non-linear analysis and linear analysis fall in the same range. This is due to the non-linear analysis with $\beta<1$ and larger $\gamma_{\mathrm{y}}$, and the linear analysis, on the other hand, with $\beta=1$ and smaller $\gamma_{\mathrm{y}}$. It is also noted that the values of $p_{0}$ estimated by non-linear analysis and linear analysis are close to those estimated by the lift-off method. The lift-off pressure is $449 \mathrm{kPa}$ in London clay and $480 \mathrm{kPa}$ in Singapore marine clay, respectively.

It is realized that the lift-off pressure is affected by the excess pore water pressure $\Delta u_{i}$ caused by the insertion of the pressuremeter. Fig. 11 shows that the lift-off pressure for

Table 2. Comparison of non-linear and linear analyses in the estimations of the stiffness parameters at yielding and the cavity reference pressure

\begin{tabular}{|c|c|c|c|c|c|c|c|}
\hline \multirow[t]{2}{*}{ Test } & \multirow{2}{*}{$\begin{array}{l}\text { Loop } \\
\text { no. }\end{array}$} & \multicolumn{3}{|c|}{ Non-linear analysis } & \multicolumn{3}{|c|}{ Linear analysis } \\
\hline & & $G_{\mathrm{y}}: \mathrm{MPa}$ & $\gamma_{\mathrm{y}}: \%$ & $p_{0}: \mathrm{kPa}$ & $G_{\mathrm{ur}}: \mathrm{MPa}$ & $\gamma_{\mathrm{y}}: \%$ & $p_{0}: \mathrm{kPa}$ \\
\hline $\begin{array}{l}\text { London clay } \\
p_{\text {Limit }}=1607 \mathrm{kPa}, c_{\mathrm{u}}=178 \mathrm{kPa}\end{array}$ & $\begin{array}{l}1 \\
2 \\
3\end{array}$ & $\begin{array}{l}20 \cdot 6 \\
16 \\
17\end{array}$ & $\begin{array}{l}0 \cdot 86 \\
1 \cdot 11 \\
1 \cdot 05\end{array}$ & $\begin{array}{l}475 \\
496 \\
485\end{array}$ & $\begin{array}{l}43 \cdot 5 \\
34 \cdot 3 \\
29 \cdot 6\end{array}$ & $\begin{array}{l}0.41 \\
0.52 \\
0.60\end{array}$ & $\begin{array}{l}451 \\
493 \\
519\end{array}$ \\
\hline $\begin{array}{l}\text { Singapore marine clay } \\
p_{\text {Limit }}=766 \mathrm{kPa}, c_{\mathrm{u}}=39.3 \mathrm{kPa}\end{array}$ & $\begin{array}{l}1 \\
2\end{array}$ & $\begin{array}{r}10 \cdot 2 \\
8 \cdot 5\end{array}$ & $\begin{array}{l}0 \cdot 39 \\
0 \cdot 46\end{array}$ & $\begin{array}{l}485 \\
485\end{array}$ & $\begin{array}{l}12 \cdot 5 \\
12 \cdot 2\end{array}$ & $\begin{array}{l}0 \cdot 31 \\
0 \cdot 32\end{array}$ & $\begin{array}{l}500 \\
501\end{array}$ \\
\hline
\end{tabular}


Table 3. Estimating $\sigma_{\mathrm{ho}}^{\prime}$ and $K_{0}$ in Singapore marine clay considering the effect of $\Delta u_{i}$

\begin{tabular}{c|c|c|c|c|c|c}
\hline \multirow{2}{*}{$\begin{array}{c}\text { Loop } \\
\text { no. }\end{array}$} & \multicolumn{2}{|c|}{ Lift-off } & \multicolumn{2}{c|}{ Non-linear analysis } & \multicolumn{2}{c}{ Linear analysis } \\
\cline { 2 - 7 } & $\sigma_{\text {ho }}^{\prime}: \mathrm{kPa}$ & $K_{0}$ & $\sigma_{\text {ho }}^{\prime}: \mathrm{kPa}$ & $K_{0}$ & $\sigma_{\text {ho }}^{\prime}: \mathrm{kPa}$ & $K_{0}$ \\
\hline 1 & 65 & 0.56 & 70 & 0.60 & 85 & 0.73 \\
2 & 65 & 0.56 & 70 & 0.60 & 86 & 0.74 \\
\hline
\end{tabular}

the testing in London clay is close to the initial pore water pressure $u_{i}$. Testing in Singapore marine clay also shows that the lift-off pressure is larger than $u_{i}$, which is much larger than the static water pressure $u_{0}$. This means that $u_{i}$ consists of $u_{0}$ and $\Delta u_{i}$ for an SBP test in clayey layer. Thus, the lift-off pressure obtained from the SBP test in a clay layer is generally larger than $\sigma_{\mathrm{h} 0}$.

The value of $p_{0}$ estimated by the non-linear or linear analysis is also affected by $\Delta u_{i}$ because of $p_{\text {Limit }}$, which is estimated from the total pressure, including the effect of $\Delta u_{i}$. Therefore, without the value of $\Delta u_{i}$, the correct estimation of $\sigma_{\text {ho }}$ based on the non-linear or linear total stress analysis is impossible.

For the SBP test in Singapore marine clay, $\Delta u_{i}$ is $176 \mathrm{kPa}$ and $u_{0}$ is $239 \mathrm{kPa}$. Assuming that $u_{i}$ does not change during the SBP test, the effective in situ horizontal stress $\sigma_{\text {ho }}^{\prime}$ can be estimated by using $\sigma_{\text {ho }}^{\prime}=p_{0}-\Delta u_{i}-u_{0}$. Table 4 provides the values of $\sigma_{\text {ho }}^{\prime}$ and the earth pressure at rest $K_{0}$. The value of $K_{0}$ ranges from 0.56 to 0.74 , which appears reasonable for the light overconsolidated marine clay with an overconsolidation ratio OCR of $1 \cdot 5$. Based on the expression suggested by Mayne \& Kulhawy $(1982), K_{0}=\left(1-\sin \phi^{\prime}\right) \mathrm{OCR}^{\sin \phi^{\prime}}$, where $\phi^{\prime}$ is the effective friction angle, the value of $K_{0}$ is 0.71 for the marine clay.

\section{Author's reply}

We welcome the opportunity to recognize the achievements of the senior discusser, not least in the field of cavity expansion analysis. The independent analyses in 1972 of both Ladanyi and Palmer, in performing an elegant transformation from pressuremeter measurements to shear stress-strain data for isotropic soil, are well known to us, as they should be to every research worker in this field.

It is possible to share the discussers' exasperation that original research fails to penetrate engineering practice, but it would be unwise to ignore the facts. Linear elastic-perfectly plastic solutions based on Gibson and Anderson are widely used to derive parameters for engineering consultants who demand them. These engineers presumably do not know of the errors that may be generated by this unnecessary restriction. In our view, the neglect of Professor Ladanyi's more fundamental approach is due principally to its main achievement-displaying shear data without the need for parameters. Engineers want parameters. The modest aims of the Technical Note were:

(a) to demonstrate that real data from overconsolidated soils fit a power curve for the stress-strain law prior to full mobilization of shear strength

(b) to show that interpretations based on the false assumption of a linear-elastic perfectly plastic soil model are significantly misleading.

The discussers are obviously disconcerted with our presentation of the theory for power law soils in a fashion that might appeal to practising engineers. We admit we were unaware of the similar power law solution published by the senior discusser, 24 years ago, in a paper on the bearing capacity of strip footings on frozen soils. However, we were surprised that the discussers were not as pleased as we were with the excellent fit obtained by analysing field data in stiff clays using power curves. Recent work on clastic compression at Cambridge (McDowell \& Bolton, 1998) has improved our understanding of how and why soils may adopt limited fractal structures during initial normal consolidation, and it is well known that power laws inevitably emerge from fractal structures.

Of course, we realize that different parameters must apply to the three different ranges of soil behaviour corresponding respectively to elasticity, rearrangement and crushing of the grains. We concentrated on the broad middle range of particle rearrangement, during which the tangent shear modulus continuously reduces as shear strain increases (the misnamed S-curve). We selected a power law for this range of behaviour, and did not quote stiffness parameters for shear strains smaller than $10^{-4}$. Nor did we attempt to resolve the impact of volumetric hardening due to grain crushing, which might make the fitting of power curves to the large-strain data of normally consolidated soils rather less accurate.

Non-linearity of soils is both manifest and important in the strain range $10^{-4}$ to $10^{-2}$, which covers most geotechnical designs. The practical consequences of non-linearity for the behaviour of engineering structures are well documented in research publications, but possibly not so widely known by practising engineers. Where unload-reload data from pressuremeter tests happen to fit a power law for these small-to-medium strains, simple power law expressions are available to represent the deformation of soils below foundations, or adjacent to walls or piles (Bolton, 1993). Our Note enables engineers to obtain the index $\beta$ and yield strain $\gamma_{\mathrm{y}}$ that best describe the degree of non-linearity, together with the undrained shear strength $c_{\mathrm{u}}$, so that they can use these parameters directly in their designs.

\section{Cao}

The authors thank Cao for his interest. In particular, we agree that equation (19) in the Note should have been set so that the exponent -1 on the right-hand side of the equation applied to the calculated exponential result, not (apparently) to its argument.

With regard to the origin for stress and strain, alluded to in the discusser's equation (27), we note that this was not broached in the paper. However, a longer discussion about the variation in the initial state of the soil following insertion of the instrument can be found in Whittle (1999). The question is then raised of lift-off pressure in relation to possible excess pore pressures following insertion. Excess pore pressures are, as we showed, a natural concomitant of non-linear stress-strain laws. Pore pressures induced by over-cutting or under-cutting on insertion may, therefore, be treatable as a byproduct of our analysis requiring no further corrective action. We agree that the power curve analyses of the data introduced by the discusser seem reasonable.

The further use of the power law fitting to interpret the effects of disturbance during installation on the results of selfboring PMTs, leading to better estimates of $p_{0}$, can be found in Whittle (1999).

\section{REFERENCES}

Bolton, M. D. (1993). Design methods. In Prediction and performance in geotechnical engineering, pp. 50-71. London: Thomas Telford.

Denby, G. M. \& Clough, G. W. (1980). Self-boring pressuremeter tests in clay. J. Geotech. Engng, ASCE, 106, GT12, 1369-1378.

Ladanyi, B. (1972). In situ determination of undrained stress-strain behaviour of sensitive clays with the pressuremeter. Can. Geotech. J. 9, 313-319.

Ladanyi, B. (1975). Bearing capacity of strip footings in frozen soils. Can. Geotech. J. 12, 393-407.

Ladanyi, B. \& Johnston, G. H. (1973). Evaluation of in situ creep properties of frozen soils with the pressuremeter. Proceedings of the 2nd international conference on permafrost, Yakutsk. North American Contribution Volume. pp. 310-318. Washington: National Academy of Sciences. 
Ladanyi, B. \& Johnston, G. H. (1974). Behaviour of circular footings and plate anchors embedded in permafrost. Can. Geotech. J. 11, 531-552.

Mayne, P. W. \& Kulhawy, F. H. (1982). $\mathrm{K}_{0}-\mathrm{OCR}$ relationship in soils. J. Geotech. Engng, ASCE 108, No. GT6, 851-872.

McDowell, G. R. \& Bolton, M. D. (1998). On the micro-mechanics of crushable aggregates. Géotechnique 48, No. 5, 667-697.

Palmer, A. C. (1972). Undrained plane-strain expansion of a cylindrical cavity clay: a simple interpretation of the pressuremeter test. Géotechnique 22, No. 3, 451-457.

Whittle, R. W. (1999). Using non-linear elasticity to obtain the engineering properties of clay. Ground Engng 32, No. 5, 30-34. 